\title{
Intracellular insulin in human tumors: examples and implications
}

\author{
Razvan T Radulescu
}

\begin{abstract}
Insulin is one of the major metabolic hormones regulating glucose homeostasis in the organism and a key growth factor for normal and neoplastic cells. Work conducted primarily over the past 3 decades has unravelled the presence of insulin in human breast cancer tissues and, more recently, in human non-small cell lung carcinomas (NSCLC). These findings have suggested that intracellular insulin is involved in the development of these highly prevalent human tumors. A potential mechanism for such involvement is insulin's binding and inactivation of the retinoblastoma tumor suppressor protein (RB) which in turn is likely controlled by insulin-degrading enzyme (IDE). This model and its supporting data are collectively covered in this survey in order to provide further insight into insulin-driven oncogenesis and its reversal through future anticancer therapeutics.
\end{abstract}

\section{Introduction}

It has meanwhile been nearly a century since insulin's stimulatory effects on cell proliferation and tissue growth have been studied [1-3]. Thereby, insulin's growth-promoting actions have mainly been attributed to its complex formation with the insulin receptor located on the surface of various cells and cloned in the mid-1980s [4] along with the second messenger cascades initiated by such heterodimerization [5].

However, historically preceding and coinciding with this model on an extracellular insulin activity, there have also been reports of direct - i.e. (non-insulin receptor-mediated and) intracellular-insulin effects at the level of the cell nucleus [6] and, moreover, on RNA and protein synthesis by intracellular insulin [7] as well as on the transcription of immediate-early genes by intranuclear insulin [8].

In the early 1990s, this conceptual framework on an intracellular localization and action of insulin was expanded by a novel proposal according to which insulin may physically interact with the (mainly nuclear) retinoblastoma tumor suppressor protein (RB) and thereby, similar to RB-binding viral oncoproteins, inactivate RB and thus promote cell proliferation [9] which was subsequently validated experimentally [10-13], primarily in human tumor cell culture models [11-13]. The

Correspondence: ratura@gmx.net

Molecular Concepts Research (MCR), Münster, Germany present review will focus on delineating this potential intracellular signal transduction pathway for insulin, thereby taking primarily into account human cell line and tissue studies as well as its possible inhibition by anticancer drug candidates directly targeting this molecular avenue.

\section{Dual mode of insulin signalling}

As a result of an insulin-insulin receptor interaction in the presence of low nanomolar insulin concentrations, a second messenger cascade is activated among which the intracellular enzyme phosphatidylinositol 3-kinase (PI 3kinase) is a major intermediary molecule [14]. Further downstream from PI 3-kinase, this cascade leads to Ras activation and, ultimately, to retinoblastoma protein inactivation through the latter's hyperphosphorylation [15], the outcome of this cascade being cell cycle progression and increased cell proliferation.

In addition to this signalling cascade initiated by insulin at the level of the cell membrane, it has become increasingly apparent over the past three and a half decades that insulin could also act as its own messenger (i.e. without the mediation of other molecules) in order to directly promote cell growth, specifically insulin molecules that are located intracellularly.

The main support for such a possibility comes from studies conducted on human cancer tissue specimens and revealing the presence of intratumoral insulin [16-19]. Intriguingly, one of these studies reported not 
Table 1 The "IDE switch": a) surges (particularly those of a pathological nature) in the extracellular/blood level of insulin and b) defects in the activity of intracellular IDE are functionally equivalent to one another in that they both lead to an increase in intracellular insulin, the former through augmented insulin internalization [31] and the latter through decreased insulin degradation

\begin{tabular}{ccccc}
\hline Extracellular/blood insulin & Intracellular IDE activity & Intracellular insulin & Intracellular insulin-RB heterodimers & Cell proliferation \\
\hline Normal & Normal & Minimal & Minimal & Normal \\
\hline Increased $^{*}$ & Normal & Increased & Increased & Increased \\
\hline Normal/Increased* $^{*}$ & Defective & Increased & Increased & Increased \\
\hline
\end{tabular}

*i.e. hyperinsulinemia.

As a result, elevated intracellular insulin stimulates cell proliferation by binding and thereby inactivating the RB tumor suppressor, both in neoplastic diseases and in aging-related morbidities such as Syndrome $X$ or, respectively, the metabolic syndrome which includes various clinical manifestations such as hyperinsulinemia, insulin resistance, obesity, type 2 diabetes and hypertension [32]. Interestingly, this model is supported by experimental data revealing increased intracellular insulin concentrations in monocytes from obese patients and obese diabetic patients vs. those from normal subjects [33].

only the detection of cytoplasmic insulin, but also of nuclear insulin [17]. These investigations indicated the possibility that such intracellular insulin may contribute to the pathogenesis of these neoplasias.

A potential mechanism for such intracellular insulindriven tumor growth is the insulin-RB complex formation that, so far, has been experimentally demonstrated in several human carcinoma-derived cell lines [11-13]. This intracellular complex would be expected to occur primarily in the nuclei of such tumors, but a cytosolic presence of this heterodimer is also conceivable both of which subcellular localizations ought to be addressed in future studies, e.g. by employing lysates of primary tumors obtained from cancer patients.

Furthermore, the probability for this interaction should be higher in neoplastic cells which equally display a dysfunction of insulin-degrading enzyme (IDE) or, respectively, insulysin in the light of previous data showing that an inactivation of IDE leads to an increase in the nuclear localization of insulin [20]. In this context, it is interesting to note that the same compound (1,10-phenanthroline) used to block IDE activity [20] has also been shown to decrease the formation of the tumor-suppressive wildtype conformation of the p53 protein [21].

Therefore, the resulting concept on IDE as a potential tumor suppressor protecting RB from inactivation by insulin, as elaborated through structural [22-24] and proteomic $[25,26]$ studies, should remain an additional important element to be further investigated in order to better understand cancer promotion by insulin in the years ahead. In this context, the following model may be useful in guiding such upcoming efforts (Table 1).

In case the envisaged insulin-RB complexes and IDE dysfunction will be validated in human cancer specimens, this would then suggest as an antineoplastic treatment strategy the interference with such intracellular carcinogenesis by means of cell-penetrating peptides that bind and thereby neutralize insulin such as those peptides derived from $\mathrm{RB}$ and termed MCR peptides [11,13,27-30].
Competing interests

The author declares having no competing interests.

Received: 25 January 2011 Accepted: 1 April 2011 Published: 1 April 2011

\section{References}

1. Gey GO, Thalhimer W: Observations of the effects of insulin introduced into the medium of tissue cultures. JAMA 1924, 82:1609.

2. Salter J, Best CH: Insulin as a growth hormone. Br Med J 1953, 2:353-356.

3. Messina $\mathrm{L}$ : Insulin as a growth-promoting hormone. In Handbook of Physiology. Volume V. Hormonal Control of Growth, Oxford University Press; 1999:783-811.

4. Ullrich A, Bell JR, Chen EY, et al: Human insulin receptor and its relationship to the tyrosine kinase family of oncogenes. Nature 1985, 313:756-761

5. Rosen OM: After insulin binds. Science 1987, 237:1452-1458.

6. Goldfine ID, Smith GJ, Wong KY, Jones AL: Cellular uptake and nuclear binding of insulin in human cultured lymphocytes: evidence for potential intracellular sites of insulin action. Proc Natl Acad Sci USA 1977 74:1368-1372

7. Miller DS: Stimulation of RNA and protein synthesis by intracellular insulin. Science 1988, 240:506-509.

8. Lin YJ, Harada S, Loten EG, Smith RM, Jarett L: Direct stimulation of immediate-early genes by intranuclear insulin in trypsin-treated H35 hepatoma cells. Proc Natl Acad Sci USA 1992, 89:9691-9694.

9. Radulescu RT, Wendtner CM: Proposed interaction between insulin and retinoblastoma protein. J Mol Recognit 1992, 5:133-137.

10. Radulescu RT, Bellitti MR, Ruvo M, Cassani G, Fassina G: Binding of the LXCXE insulin motif to a hexapeptide derived from retinoblastoma protein. Biochem Biophys Res Commun 1995, 206:97-102.

11. Radulescu RT, Doklea E, Kehe K, Mückter H: Nuclear colocalization and complex formation of insulin with retinoblastoma protein in HepG2 human hepatoma cells. J Endocrinol 2000, 166:R1-R4.

12. Radulescu RT, Schulze J: Insulin-retinoblastoma protein (RB) complex further revealed: intracellular RB is recognized by agarose-coupled insulin and co-immunoprecipitated by an anti-insulin antibody. Logical Biol 2002, 2:2-10.

13. Radulescu RT, Kehe K: Antiproliferative MCR peptides block physical interaction of insulin with retinoblastoma protein (RB) in human lung cancer cells. arXiv 2007 [http://arxiv.org/abs/0706.1991], 0706.1991v1 [q-bio.SC]

14. Chappell J, Leitner JW, Solomon, Golovchenko I, Goalstone ML, Draznin B: Effect of insulin on cell cycle progression in MCF-7 breast cancer cells. J Biol Chem 2001, 276:38023-38028.

15. Sears RC, Nevins JR: Signaling networks that link cell proliferation and cell fate. J Biol Chem 2002, 277:11617-11620.

16. Castro A, Ziegels-Weissman J, Buschbaum P, Voigt W, Morales A, Nadji M: Immunochemical demonstration of immunoreactive insulin in human breast cancer. Res Commun Chem Pathol Pharmacol 1980, 29:171-182.

17. Spring-Mills EJ, Stearns SB, Numann PJ, Smith PH: Immunocytochemical localization of insulin- and somatostatin-like material in human breast tumors. Life Sci 1984, 35:185-190. 
18. Radulescu RT, Hufnagel C, Luppa P, et al: Immunohistochemical demonstration of the zinc metalloprotease insulin-degrading enzyme in normal and malignant human breast: correlation with tissue insulin levels. Int J Oncol 2007, 30:73-80.

19. Mattarocci S, Abbruzzese C, Mileo AM, et al: Intracellular presence of insulin and its phosphorylated receptor in non-small cell lung cancer. J Cell Physiol 2009, 221:766-770.

20. Harada S, Smith RM, Smith JA, Jarett L: Inhibition of insulin-degrading enzyme increases translocation of insulin to the nucleus in $\mathrm{H} 35$ rat hepatoma cells: evidence of a cytosolic pathway. Endocrinology 1993, 132:2293-2298.

21. Hainaut P, Milner J: A structural role for metal ions in the "wild-type" conformation of the tumor suppressor protein p53. Cancer Res 1993, 53:1739-1742

22. Radulescu RT: unpublished observation 1994.

23. Radulescu RT: Zinc-binding motif similarity between retinoblastoma protein (RB) and insulin-degrading enzyme (IDE): insulin degradation as a potential tumor suppression principle. Logical Biol 2005, 5:3-6.

24. Radulescu RT: Tumor suppressor and anti-inflammatory protein: an expanded view on insulin-degrading enzyme (IDE). arXiv 2008 [http://arXiv.org/abs/0812.0160], 0812.0160v1 [q-bio.BM].

25. Radulescu RT, Poznic M, Pavelic K: Complex formation between metabolic enzymes in tumor cells: unfolding the MDR1-IDE paradigm. Mol Cancer Ther 2009, 8:3171.

26. Radulescu RT, Duckworth WC, Levy JL, Fawcett J: Retinoblastoma protein co-purifies with proteasomal insulin-degrading enzyme: implications for cell proliferation control. Biochem Biophys Res Commun 2010, 395:196-199.

27. Radulescu RT, Jaques G: Selective inhibition of human lung cancer cell growth by peptides derived from retinoblastoma protein. Biochem Biophys Res Commun 2000, 267:71-76.

28. Radulescu RT, Jaques $G$ : Potent in vivo antineoplastic activity of MCR peptides MCR-4 and MCR-14 against chemotherapy-resistant human small cell lung cancer. Drugs Exp Clin Res 2003, 29:69-74.

29. Radulescu RT: Going beyond the genetic view of cancer. Proc Natl Acad SCi USA 2008, 105:E12.

30. Radulescu RT, Fahraeus R: Targeting the RB pathway for cancer therapy: peptide mimetic foundations and promise. Am J Transl Res 2010, 2:209.

31. Smith RM, Jarett L: Partial characaterization of mechanism of insulin accumulation in H35 hepatoma cell nuclei. Diabetes 1990, 39:683-689.

32. Radulescu RT: Insulin-RB heterodimer: potential involvement in the linkage between aging and cancer. Logical Biol 2006, 6:81-83.

33. Benzi L, Ciccarone AM, Cecchetti P, et al: Intracellular hyperinsulinism: a metabolic characteristic of obesity with and without type 2 diabetes: intracellular insulin in obesity and Type 2 diabetes. Diabetes Res Clin Pract 1999, 46:231-237.

doi:10.1186/1758-5996-3-5

Cite this article as: Radulescu: Intracellular insulin in human tumors: examples and implications. Diabetology \& Metabolic Syndrome 2011 3:5.

\section{Submit your next manuscript to BioMed Central and take full advantage of:}

- Convenient online submission

- Thorough peer review

- No space constraints or color figure charges

- Immediate publication on acceptance

- Inclusion in PubMed, CAS, Scopus and Google Scholar

- Research which is freely available for redistribution 